\title{
Experimental, Cross-cultural, and Classical Indian Epistemology*
}

John Turri

Philosophy Department and Cognitive Science Program

University of Waterloo

200 University Avenue West

Waterloo, Ontario N2L3G1, Canada

john.turri@gmail.com

Abstract: This paper connects recent findings from experimental epistemology to several major themes in classical Indian epistemology. First, current evidence supports a specific account of the ordinary knowledge concept in contemporary anglophone American culture. According to this account, known as abilism, knowledge is a true representation produced by cognitive ability. I present evidence that abilism closely approximates Nyāya epistemology's theory of knowledge, especially that found in the Nyāya-sütra. Second, Americans are more willing to attribute knowledge of positive facts than of negative facts, especially when such facts are inferred and even when the positive and negative "facts" are logically equivalent. Similar suspicions about knowledge of negative facts (absences) seemingly occur in classical Indian epistemology, suggesting that the asymmetry might not be an American quirk but instead reflect a cross-culturally robust tendency in knowledge attributions. Each of these themes - abilism and the positive/negative asymmetry — presents an exciting opportunity for further research in experimental cross-cultural epistemology.

Keywords: Nyāya; abilism; knowledge; source-content bias; experimental epistemology

* This is the penultimate version of a paper forthcoming in Journal of Indian Council of Philosophical Research. Please cite the final, published version if possible. 


\section{Introduction}

Philosophers undertake a diverse range of projects, including projects that are relatively unconstrained by commonsense commitments. For example, some logicians focus on relations of logical consequence in formal systems; some metaphysicians interpret findings from cosmology or quantum physics; some philosophers of mind develop systematic theories of human cognition in light of evidence from biology, anthropology, psychology, and neuroscience. It would be completely unsurprising if these philosophers' conclusions struck us as unintuitive or even bizarre. This is largely because these conclusions pertain to extremely complicated and unfamiliar phenomena and there is no reason to suppose that our untutored or pretheoretical intuitions are suited to deal effectively with such matters. For instance, even though we are familiar with visible light and with forming memories, we have no pretheoretical intuitions about quantum wave functions or the hippocampus's role in memory formation.

But philosophers often pursue projects that are, in important ways, constrained by commonsense. For instance, many philosophers investigate concepts familiar from everyday life, such as knowledge, assertion, action, mentality, and obligation. One motivation for studying these concepts is that they shape our understanding of ourselves and our relationships with others. Indeed, in some hard to specify way, it seems that these concepts help make us who we are - we would be different people if we were unable to categorize one another as knowing, communicating, acting, experiencing, or obligated (Sellars 1963, ch. 1). And we do have pretheoretical intuitions about when a person, for instance, knows something or is obligated to do something. Thus it is 
surprising when philosophers draw bizarre or unintuitive conclusions about such matters. For example, we routinely confidently attribute knowledge of the immediate physical environment to ourselves and others, which probably helps explain why we find it so counterintuitive and vexatious when a skeptic staunchly denies that such things are ever known. To take another example, visual experience presents an array of seemingly separable, independent objects that frequently move and change, which probably helps explain why it seems counterintuitive when a metaphysician claims that everything is one or that nothing ever changes.

For thousands of years, philosophers in the Western tradition have appealed to patterns in commonsense judgment in order to guide theorizing about such categories. For instance, Aristotle said that we should evaluate philosophical theories on a topic "in the light of" things "commonly said about it" (Aristotle 350 BCE/1941, 1098b, 9-11). The eighteenth-century Scottish philosopher Thomas Reid wrote, "Philosophy has no other root but the principles of Common Sense," and that "severed from this root, its honours wither, its sap is dried up, it dies and rots" (Reid 1764/1997, p. 19). This approach remained popular in the twentieth-century anglophone philosophy, most conspicuously in "ordinary language philosophy," according to which "ordinary language" should get "the first word" in philosophical theorizing (Austin 1956, p. 11). Similarly, philosophers in the classical Indian tradition also treat commonsense, as reflected in ordinary language, "as a starting point for theorizing" in philosophy (Phillips 2015: §1.2). For example, on Gautama's view (Gautama 200/1913), a good argument involves an "example" or "familiar instance" illustrating a connection "to the satisfaction of an ordinary man as well as an acute investigator" (Nyāya-sütra: 1.1.25, 1.1.32). Of course, all these philosophers would ac- 
knowledge that commonsense can be misguided and that ordinary concepts can be improved and, in some cases, should probably be discarded or replaced. The point is not that commonsense is invariably or even usually correct. But if theorizing disconnects from commonsense views, then it will not be about the concepts in question. Instead, the theorist will have changed the subject.

In this context, it is easy to appreciate one motivation for what has come to be known as experimental philosophy (for some reviews, see Knobe et al. 2011; Alexander 2012; Beebe 2012; Sytsma \& Livengood 2015; Sytsma \& Buckwalter 2016). To the extent that philosophers aim to understand ordinary concepts and practices, they should rely on methods and findings from allied disciplines that investigate similar questions, such as linguistics and psychology. A few simple behavioral experiments can quickly cut through researchers' misimpressions and put them on more promising paths (for discussion of examples, see Turri 2016c; Turri 2016e; Buckwalter \& Turri in press). Statistical techniques such as regression, mediation analysis, structural equation modeling, and causal search algorithms can identify complicated interactions or dependencies that even the astutest informal observation or introspection cannot glimpse (Turri \& Buckwalter 2017; Turri, Buckwalter \& Rose 2016). And neuroscience expands the possibilities even further through brain imaging, patient studies, brain stimulation, cellular recording, lesioning, and others.

In the remainder of this paper, I will review some of what experimental philosophy has discovered about the ordinary knowledge concept. More specifically, I will review studies of how adult anglophone residents of the United States attribute knowledge. I chose to review these findings for two reasons, each of which relates to this journal's primary audience. First, recent re- 
search suggests that people in the United States and India share similar knowledge concepts (Turri 2013; Machery, Stich, Rose, et al. in press). This conceptual similarity might be due to convergent conceptual development. Or it might be due to a common cultural-linguistic heritage. Historical linguists hypothesize that know in English, jānnā in Hindi, and similar expressions derived from the Sanskrit jũana are cognates derived from the Proto-Indo-European root *gnō(Calvert 2011). The similarity might also reflect a phylogenetically old knowledge concept that develops naturally as part of primate social cognition and, as a result, is shared by humans worldwide (Turri in press b). Whatever the similarity's ultimate explanation, acquainting this journal's audience with research on the knowledge concept will hopefully motivate some of them to contribute to the nascent, exciting, and growing literature in cross-cultural epistemology (important recent contributions to this field include Rose, Machery, Stich, et al. in press; Kim \& Yuan ms.). Second, discoveries reviewed here relate directly to enduring themes in classical Indian epistemology, which will hopefully increase their resonance for this journal's audience.

\section{Abilism and Nyāya}

A popular view in contemporary anglophone epistemology is reliabilism. According to this view, knowledge is true belief produced by reliable cognitive processes or faculties, or reliably produced true belief. Here reliable means that the process or faculty produces mostly true beliefs.

What are contemporary reliabilists are giving theories of? I interpret them as offering theories of the ordinary knowledge concept, a mental representation shared by members of a commu- 
nity and expressed linguistically by the verb know. This aligns with the dominant methodology of contemporary anglophone epistemology (see Turri 2016c for a review). For example, theorists claim that their view "matches our everyday practice with the concept of knowledge" (Craig 1990: 3), describes "the concepts and practices of the folk" (Goldman 1993: 272), and is motivated "by reflecting on our thinking and practices" regarding knowledge (Greco 2010: 4). On this approach, patterns in ordinary knowledge attributions provide evidence regarding the content of our knowledge concept.

One serious problem with reliabilism is that knowledge does not require belief, as those categories are ordinarily understood. If, as a conceptual matter, knowledge requires belief, then we would expect that to be reflected in the judgments of competent speakers. When researchers investigated this, they found that adult anglophones are often willing to attribute knowledge without attributing belief (Myers-Schulz \& Schwitzgebel 2013; Murray, Sytsma \& Livengood 2013). In some cases, the majority of people who attribute knowledge also deny belief. For example, participants in one study read about Karen, a first-year university student taking an introductory science course (Murray, Sytsma \& Livengood 2013). Karen's instructor and textbook teach that the earth revolves around the sun. This conflicts with what Karen's religious parents taught her growing up: they taught her that the sun revolves around the earth. On the final exam for the science course, Karen encounters the question, "True or false: the earth revolves around the sun." She answers "true." After reading the case, participants were asked whether Karen knows that the earth revolves around the sun, and whether Karen believes that the earth revolves around the sun. Of those who attributed knowledge, the vast majority (85\%) denied belief. 
Of course, even if people strongly tend to attribute knowledge only if they will also attribute belief, it does not follow that they view knowledge as involving belief. A series of recent studies using regression analysis and causal modeling suggested that even when people attributed both knowledge and belief, their knowledge attributions were not based on their belief attributions (Turri \& Buckwalter 2017; Turri, Buckwalter \& Rose 2016). And researchers found in reaction-time studies that people attribute knowledge faster than they attribute belief (Phillips, Knobe \& Cushman 2015). If knowledge attributions occur before belief attributions, then the former are not based on the latter.

What explains this conceptual disconnect between knowledge and belief? One hypothesis is that belief ordinarily understood is connected with feeling or emotion in a way that knowledge is not (Buckwalter, Rose \& Turri 2015; Buckwalter \& Turri 2016). As William James wrote, by its "inner nature," belief "is a sort of feeling more allied to the emotions than to anything else" (James 1889: 21). According to David Hume (1748/1993: 32), this is how belief is understood "in common life." By contrast, knowledge might not entail anything about how someone feels. If knowledge does not entail anything about how someone feels but belief does, then knowledge cannot entail belief. Interestingly, this contrast is an ancient feature of Indo-European linguistic and conceptual systems, which include Germanic languages, such as modern English, and Indic languages, such as Sanskrit and its descendants. The reconstructed Proto-Indo-European language is commonly hypothesized to have existed around 3500 BCE (Anthony 2007: chapters 3-4), though some theorists favor older dates. Proto-Indo-Europeans distinguished sharply between attributions of knowledge (strongly associated with sight) and attributions of 
belief (strongly associated with the heart). On the Proto-Indo-European view, belief was viewed as not only a "cognitive process" but also "an act of faith" (Mallory \& Adams 2006: 349). Another hypothesis, consistent with the first, is that the belief concept is essentially connected to distinctively human conversational practices of explicitly justifying and excusing behavior, whereas the knowledge concept is essentially connected to the much older animal practice of predicting behavior (Turri in press b). On this hypothesis, the two concepts play different roles in our social-cognitive economy, there is no reason to expect entailment, and we would expect judgments about knowledge and belief to diverge in the sorts of cases where they have been observed to diverge.

A second serious problem for reliabilism is that knowledge does not require reliability. If, as a conceptual matter, knowledge requires reliability, then we would expect that to be reflected in the judgments of competent speakers. When researchers investigated this, they found that adult anglophones attributed knowledge even when the relevant cognitive ability was accurate only ten- or thirty-percent of the time. Rates of unreliable knowledge attribution reached $80-90 \%$. Participants consistently attributed knowledge to reliable and unreliable agents at similar rates, they attributed knowledge despite actively classifying the knower as unreliable, and they declined to attribute knowledge in closely matched controls involving agents who guess correctly or answer incorrectly. More generally, although people understood and processed explicit information about reliability, apparently they did not consult this information when making knowledge judgments.

To illustrate, in one study, participants were divided into two groups (Turri 2016: experi- 
ment 4). They all read a story about Alvin, who has been out running errands all day. In the morning, Alvin's wife told him that he should stop at the dry cleaners. On his way home, Alvin stops at the dry cleaners. Participants in the unreliable condition were also told that Alvin's memory is unreliable; participants in the reliable condition were told that Alvin's memory is reliable. That was the only difference. Participants then judged whether Alvin knows that he should stop at the dry cleaners. In the unreliable condition, participants categorized Alvin as unreliable and $86 \%$ of them attributed knowledge. In the reliable condition, participants categorized Alvin as reliable and $88 \%$ of them attributed knowledge. The same pattern occurred when using different dependent measures, different narrative contexts, for male and female agents, and for different faculties.

Ordinary knowledge attributions might not be based on information about reliability, but there is evidence that they are based on information about ability. In one study, adult participants completed two tasks: they decided whether an agent reached the correct answer by ability or luck, and they judged whether the agent knows the answer (Turri 2016a: experiment 7). Participants credited luck when the answer was based on a guess, but they credited ability when the agent exercised her ability. And knowledge judgments were strongly positively correlated with crediting ability. In another study, researchers manipulated whether an agent repeatedly misidentifies objects of a certain type before finally correctly identifying one on the final trial, or she correctly identifies one on her first try. Participants rated whether the agent knows that it is an object of that type (a knowledge attribution), whether the agent is able to identify objects of that type (an ability attribution), and the quality of the agent's evidence (an evidence evaluation). Re- 
searchers found that ability attributions caused knowledge attributions and, moreover, completely mediated the manipulation's effect on knowledge attributions (Turri in press c: results for the "unspecified" conditions). By contrast, knowledge attributions were not based on evidence evaluations.

Relatedly, researchers have found that even after observing a speaker consistently mislabel objects (e.g. calling keys "pencils"), 3-5 year old children accept this unreliable speaker's label for a novel item, as indicated by the fact that they use the label to refer to other similar items and they expect third-parties to also use it similarly (Kim, Paulus \& Kalish 2016). In each respect label-use and third-party expectations - children trusted speakers observed to be unreliable no less than they trusted speakers observed to be reliable (Kim, Paulus \& Kalish 2016: experiment 1). And this is not because children at this age trust indiscriminately or cannot understand reliability: they do not trust a speaker when they have clear evidence that the speaker is wrong or uninformed (Clément, Koenig, M, \& Harris 2004; Kim, Paulus \& Kalish 2016: experiment 3), they can distinguish between reliable and unreliable informants (Koenig, Clément \& Harris 2004; Corriveau, Meints \& Harris 2009), and they prefer to learn from reliable informants when given a choice (Koenig \& Harris 2005; Jaswal \& Neely 2006; Corriveau \& Harris 2009). Nevertheless, children still trust and base expectations on an unreliable speaker's assertions, which suggests that they implicitly attribute knowledge to unreliable speakers.

In light of existing evidence, we can conclude that reliabilism fails as a theory of the ordinary knowledge concept. But another theory fits existing evidence very well: abilism. According to abilism, knowledge is an accurate representation produced by cognitive ability (for defenses, 
see Turri 2012; Turri 2015b; Turri 2016a; Turri 2016b; Turri in press a). The representation might be a belief or it might take some other form, such as a perceptual experience, memory trace, or avowal. The relevant ability could be reliable or unreliable. There are theoretical arguments motivating abilism (see Turri 2012; 2015d). For instance, consider a twelve-month old human infant just beginning to walk. The infant is highly unreliable at walking but nevertheless some of her first steps are genuine accomplishments. In general, accomplishments occur along the road to proficiency and do not require abilities that usually succeed. Therefore, since knowledge is an intellectual accomplishment, we should not expect it to require abilities that usually succeed. But, theoretical arguments aside, for present purposes the important thing is that abilism can explain the behavioral data. Abilism can explain why people attribute knowledge to agents who get the right answer through unreliable ability. It can explain why people deny knowledge to agents who get the right answer through guessing. It can explain why information about reliability does not affect knowledge attributions whereas information about ability does. It can explain why knowledge attributions are based on ability attributions. And it can explain why people attribute knowledge without belief.

Abilism is simple and clear enough to generate some firm initial predictions that have been vindicated. But a fuller evaluation requires additional work. For instance, it is an empirical question which cognitive abilities commonsense psychology presupposes. Assuming that commonsense psychology attributes to agents the cognitive abilities of perception, memory, and inference, then abilism predicts that, in practice, knowledge attributions will amount to the detection (perception), retention (memory), or discovery (inference) of truths. If other cognitive abilities 
are presupposed, then abilism predicts that knowledge will be attributed on those bases too. For instance, along with Nyāya epistemology, commonsense might include receptivity to "instructive assertion" as a distinct cognitive ability (Nyāya-sütra 1.6), in which case people would attribute knowledge for information acquired by such means. Similarly, abilism predicts that individual differences or cultural factors affecting how people judge abilities will also affect how they attribute knowledge. For example, if certain personality traits or cultural backgrounds make people more likely to accept yogic or other mystical perceptual abilities, then abilism predicts that those people are more likely to attribute knowledge in cases where such abilities are (allegedly) exercised. Essentially, accepting that such abilities exist expands the range of truths that one thinks individuals can detect.

Interestingly, when combined with recent evidence from primatology, abilism suggests that the core human knowledge concept is inherited as part of the primate social-cognitive system. Over the past two decades, based on a series of remarkable studies utilizing a food-competition paradigm, primatologists have concluded that non-human primates, especially apes, represent others as having knowledge and, thus, have a knowledge concept (Hare, Call, Agnetta \& Tomasello 2000; Hare, Call \& Tomasello 2001; Flombaum \& Santos 2005; Santos, Nissen \& Ferrugia 2006; Melis, Call \& Tomasello 2006; Kaminski, Call \& Tomasello 2008; Marticorena, Ruiz, Mukerji, Goddu \& Santos 2011; for reviews, see Call \& Tomasello 2008; Seed \& Tomasello 2010; Martin \& Santos 2016). This primate concept pertains to the detection, discovery, and retention of truths and is closely connected to predicting others' behavior and guiding decisionmaking. For instance, researchers found that subordinate chimpanzees keep track of which food 
items dominant chimpanzees currently see or recently saw and use this information to decide which food items to retrieve. Related studies show that chimpanzees actively conceal visual and auditory information from others and even attribute simple inferences to others and use this information to guide decision-making (Schmelz, Call \& Tomasello 2011; Hall, Oram, Campbell, Eppley, Byrne \& de Wall 2016).

The human knowledge concept appears to resemble the primate concept in content and function. The evidence reviewed above implies similarity of content: knowledge is, roughly, the detection, retention, or discovery of truths. A different line of research suggests similarity of function. In studies involving anglophone adults, participants read scenarios and predicted how an agent will behave, whether the agent knows a relevant proposition, and whether the agent believes the proposition. According to the dominant "belief-desire" paradigm in theory-of-mind research, belief attributions guide behavioral predictions, leaving little if anything for knowledge attributions to contribute (e.g. Rakoczy 2009; Southgate \& Vernetti 2014). But when researchers studied the issue directly, they observed a different pattern. When predicting behavior, participants relied more on knowledge attributions than belief attributions (Turri in press b: experiment 1). Moreover, in a reaction-time study, behavioral predictions were reliably faster when participants received information about what an agent knows compared to information about what the agent believes (Turri in press b: experiment 2). Thus in human and non-human primates, knowledge attributions play a critical role in predicting behavior, which is a central aspect of social cognition.

Some scholars claim that Nyāya epistemologists were the original reliabilists, with pramāna or "knowledge sources" being identified with reliable cognitive processes or faculties (e.g. 
Ganeri 1990: 237; Patil 2009: 34; Dasti, 2017). However, this could be challenged in at least two ways. Interestingly, each of these challenges corresponds to one of the serious problems facing reliabilism, which I reviewed above.

On the one hand, it is not clear that Nyāya epistemologists claimed that knowledge requires belief. A leading anglophone scholar of classical Indian epistemology characterizes the Nyāya theory of knowledge as follows, "Knowledge is cognition that has been produced in the right way," and then adds that cognitions "are not species of belief" (Phillips 2015). Another contemporary scholar writes that Nyāya defines knowledge as "an apprehension of some object, which is definite and non-erroneous" (Bhatt 1989: 80). Of course, cognition and apprehension must involve some kind of representation or attribution of a property to an object, but this need not take the form of a belief, as that category is ordinarily understood. This is not to say that Nyāya epistemology does not recognize belief. Nevertheless, rather than being a constituent or requirement of knowledge or action on the Nyāya view, belief instead seems to occur once confusion, doubt, or disagreement arises regarding an issue.

On the other hand, it is not clear that Nyāya epistemologists claimed that knowledge requires reliability. Consider Gautama's definition of perception at Nyāya-sütra 1.1.4. One translation reads, "Perceptually produced cognition arises from the connection of sense faculty and sense object, does not depend on language (avyapadeśyam), is inerrant (avyabhichäri), and is definite (vyavasāyātmaka)" (Dasti 2012: 2). The term "inerrant" suggests not mere reliability but infallibility of perception, which raises skeptical concerns and a host of thorny questions about the nature of perception, error, and illusion. If perception is infallible, meaning that it could not 
produce a false representation, then it is doubtful that humans are capable of perception. In response, one approach is to reinterpret the passage so that perception and other pramannas are "fallible but on the whole reliable knowledge-producing mechanisms" (Dasti 2012: 3). On this approach, the issue is to decide whether Nyāya epistemologists viewed knowledge as requiring fallible or infallible reliability. But another approach interprets Nyāya-sütra 1.1.4 as follows: perception is "a non-erroneous cognition produced by the intercourse of the sense-organs with objects, which is definite and independent of verbal expression" (Bhatt 1989: 152). Both approaches agree on perceptual cognition being definite and independent of language, but the second interprets avyabhichāri to mean "non-erroneous" instead of "inerrant," which is much weaker and might even simply refer to truth or representational accuracy. If this approach is on the right track, then the Nyāya theory of knowledge coheres well with abilism but not reliabilism or infallibilism, which is the view that knowledge must be produced by infallible sources.

The sutra clarifies avyabhichäri with an example: perceptual cognition of water does not occur when "in summer the sun's rays coming in contact with earthly heat quiver and appear to the eyes of men as water." Thus another translation — that of "various Sanskrit scholars" in Gautama 200 - uses the term "non-erratic" instead of "inerrant" or "non-erroneous." In my view, of those three terms, "non-erratic" makes best sense of the example. But another term might work even better because the example is reminiscent of what contemporary anglophone epistemologists call "deviant" causation (for discussion and citations, see Turri 2011). Thus another possible translation would be "non-deviant." And, as it turns out, a leading English-Sanskrit dictionary lists "non-deviation" as a sense of avyabhichāra (Monier-Williams 1964: 111). Again, if this is 
on the right track, then the Nyāya theory of knowledge coheres well with abilism because experiencing a mirage of water is not a way of sensing or detecting water, even if the experience represents properties that water actually has.

Of course, Nyāya epistemology is not monolithic and any particular contributor might disagree with the points I just made. Nevertheless, it is worth considering the possibility that Nyāya epistemologists were the original proponents of abilism. At least, it is worth considering whether an abilist interpretation of Nyāya epistemology fits better than a reliabilist or infallibilist interpretation. In my view, the fact that avyabhichāri can be translated in various ways from merely "non-erroneous" to "unerring" or even "absolute necessity" suggests that there might have been a spectrum of views within the Nyāya school on what kind of abilities knowledge requires, just as there is in contemporary anglophone epistemology, ranging from abilism to reliabilism to infallibilism.

Setting aside how to interpret long-dead Nyāya epistemologists who cannot speak for themselves, a more tractable question pertains to adults in contemporary India. Do they exhibit patterns similar to those observed in contemporary American knowledge attributions that motivate abilism as a theory of the ordinary knowledge concept? Of course, contemporary India is a vibrant multicultural society with twenty-two constitutionally recognized languages and hundreds of others belonging to at least four different language families: Indo-European, Dravidian, Austroasiatic, and Sino-Tibetan (Encyclopaedia Britannica 2015). This suggests a valuable crosscultural epistemology project, namely, investigating how much similarity is observed in knowledge attributions across some of these different languages and (sub-)cultures. Does abilism cap- 
ture a core knowledge concept shared across them all? If it does, then that is further evidence of a core knowledge concept shared universally by humans. If it does not, then that would be extremely interesting too. For instance, suppose it turned out that speakers of Indo-European languages exhibit patterns similar to those observed in Americans, whereas speakers of Dravidian languages do not. In that case, it might turn out that differences in epistemological judgments are mediated by different judgments about, say, the nature or possession of abilities. Alternatively, the results might be due to fundamental "ethnopsychological" differences (Lillard 1998) — more specifically differences in "ethnoepistemology" (Nichols, Stich \& Weinberg 2003) — perhaps traceable to deep features of language and culture that influence commonsense epistemology (Wellman, Fang, Liu, Zhu \& Liu 2006; Shahaeian, Peterson, Slaughter \& Wellman 2011).

\section{Source and Content}

Classical Indian philosophers theorized extensively about the sources of knowledge and the status of negative facts. On the one hand, they proposed detailed taxonomies of knowledge sources or cognitive abilities, always distinguishing perception from inference. Perception was accepted by all schools as a knowledge source. Inference was also widely accepted as a knowledge source though not universally. Jayarāśibhatța argued that there are no knowledge sources (Gokhale 1978) and the Cārvāka school is sometimes interpreted as denying that inference is a knowledge source (e.g. Puligandla 1996: 14), although this interpretation is based on decontextualized fragments and is debatable (Bhattacharya 2011: ch. 5). But even if all schools and contributors ac- 
cepted inference as a knowledge source, the unmistakeable impression is that perception is "the primary source" (Bhatt 1989: 146) and inference is "secondary" (Bhattacharya 2002: 612, III.2). On the other hand, classical Indian philosophers distinguished between positive facts (presence) and negative facts (absence) and they lengthily debated the metaphysics and epistemology of absence $(a b h \bar{a} v a)$ - what are absences and how, if at all, can we know that something is absent (Sharma 1966: 291)? Some argued that we know absence by perception; others argued that we know it by inference; others were dissatisfied with both positions and posited a special faculty of non-apprehension (anupalabdhi) by which absence is known (Bhatt 1989: ch. 10).

Rather than trying to relate experimental findings to any specific theoretical view on knowledge sources and absence, instead I will review some findings that suggest that these theoretical issues reflect something deep in commonsense epistemology. Perhaps the contours of theoretical discussions in classical Indian philosophy reflect "fault lines" in commonsense epistemology (compare Cushman \& Greene 2012 on moral dilemmas).

Modern Western culture has a peculiar relationship with skepticism. Skepticism is a source of fascination in popular culture and academic philosophy. Gaming boards sell lottery tickets with the slogan, "Hey, you never know." Hollywood grows rich by trafficking in serious skeptical hypotheses in films such as The Matrix (Do you know that you're not in The Matrix?), Vanilla Sky (Do you know that your life is not just a dream?), and Memento (Do you know that your past is what it seems to be?). An entire cottage industry in Western academic philosophy is devoted to understanding, arguing against, and occasionally defending the skeptic. For instance, as of this writing, the Stanford Encyclopedia of Philosophy (https://plato.stanford.edu/index.html) 
has entries for "Skepticism," "Ancient Skepticism," "Medieval Skepticism," and "Skepticism in Latin America," with many other entries devoting considerable space to skepticism, including "Moral Skepticism," "Epistemic Closure," and "Skepticism and Content Externalism." Nevertheless, like classical Indian epistemology, modern Western commonsense is resolutely anti-skeptical: in everyday life, we take ourselves and others to know many things. Moreover, engagement with skepticism in academic philosophy is principally aimed at finding ways to refute or at least resist skepticism.

This raises an interesting psychological question. If nearly no one accepts skepticism, then why do skeptical arguments fascinate us? One way to begin answering this question is to look at examples of arguments used to elicit intuitive support for skepticism. For instance, we ordinarily take ourselves to know where various objects are, such as where our cars are parked. Consider Maxwell, who just completed his workday and is about to leave his desk and head back to his car so that he can drive home. Maxwell knows that his car is parked in the parking garage. But sometimes cars are stolen. Does Maxwell know that his car is not stolen? It can easily seem that Maxwell does not know this. But, of course, Maxwell knows that if his car is parked in the garage, then it is not stolen. In light of this, the skeptic invites us to conclude that Maxwell does not know where his car is after all. And there is nothing special about Maxwell's case or about cars: the same could be said of nearly anyone not presently perceiving an object of interest.

Researchers have recently investigated why arguments like this can seem potent even though they do not persuade us that we do not know where things are. Overall, the results suggest that the argument's force is due to a combination of two factors. On the one hand, people 
view perception as a more likely source of knowledge than inference. That is, people are more likely to classify someone as knowing based on perception than on inference. On the other hand, people view inference as a more likely source of knowledge when its conclusion is that something is present (or occurring) than when its conclusion is that something is absent (or not occurring). In other words, an inference that something is the case is more likely to be classified as knowledge than an inference that something is not the case. The skeptic exploits this combination of factors when he focuses the discussion on a negative claim that, presumably, one must infer because one cannot presently check it perceptually.

In one relevant study, participants read a simple story about Maxwell, similar to the example introduced above (Turri 2015a). When he arrived at work this morning, Maxwell parked his car in the parking garage. At lunchtime, Maxwell and his assistant are in the archives room looking for a document. Then Maxwell says that he might have left the document in his car. His assistant asks where the car is parked and brings up the the possibility that the car was stolen. Maxwell responds by saying that his car is parked in the garage, so it was not stolen. The experimental conditions differed in what Maxwell did prior to responding. In the perception condition, Maxwell looks out the window. In the inference condition, he thinks for a moment. That was the only difference in how Maxwell was described. Participants then rated two critical statements: they rated whether Maxwell knows that his car is parked in the garage, which I will call a positive knowledge attribution; they also rated whether Maxwell knows that his car was not stolen, which I will call a negative knowledge attribution. In the perception conditions, the vast majority of participants attributed both positive knowledge and negative knowledge. By contrast, in the 
inference condition, although the vast majority of participants attributed positive knowledge, most participants denied negative knowledge. In other words, participants in the perception and inference conditions agreed that Maxwell knows where his car is, but they disagreed on whether Maxwell knows that his car was not stolen. Maxwell was viewed as having negative knowledge in the perception condition but not in the inference condition. The same basic pattern was observed for different testing procedures and narrative contexts (Turri 2015a: experiment 3-5; Turri 2015c: experiment 1; Beebe \& Monaghan in press: experiment 1). The same basic pattern has also been observed, in slightly attenuated form, among professional mathematicians, a highly educated population with specialization in evaluating inferences (Beebe \& Monaghan in press: experiment 4).

Occasionally, even in the perception condition, a small but statistically significant difference between positive and negative knowledge attribution occurs (e.g. Turri 2015a: experiment 2). But this occurred in a context where the vast majority still attributed positive and negative knowledge. In other words, the clear central tendency is to attribute positive and negative knowledge. By contrast, in inference conditions, the observed difference was not only statistically significant but very large and the central tendencies were opposed: people tended to attribute positive knowledge but deny negative knowledge.

The privileging of perception has been shown in different ways. Developmentally, children attribute knowledge based on perception before attributing knowledge based on non-perceptual sources (Pillow 1989). Children have difficulty denying that visual access provides knowledge (O’Neill, Astington \& Flavell 1992). And reaction-time studies suggest that this difficulty per- 
sists into adulthood (Wang, Miletich, Ramsey \& Samson 2014). One hypothesis is that perception is privileged in these ways because perceptual attributions are an older, and thus more fully integrated, feature of the primate social-cognitive repertoire. Phylogenetically, attributions of perceptual detection might have developed before attributions of inferential discovery. Humans, other apes, and monkeys all attribute perceptual detection to others (Martin \& Santos 2016), suggesting that this ability dates back tens of millions of years. By contrast, evidence for attributions of inferential discovery currently exists for only humans and other apes, specifically chimpanzees (Schmelz, Call \& Tomasello 2011; Hall, Oram, Campbell, Eppley, Byrne \& de Wall 2016), but not monkeys. One explanation for the current state of evidence is that researchers have yet to find an appropriate task for monkeys to reveal that they attribute inferential discovery to others. Another explanation is that such an ability developed only later in primate evolution, after the split between monkeys and apes, and thus more recently than the ability to attribute perceptual detection.

The suspicion of negative inferences has also been shown in a number of different ways. For instance, one study compared people's willingness to attribute inferential knowledge based on a long and unbroken track record of correlations (Turri 2015c: experiment 2). Participants read a brief story about Michelle, who visited the local zoo every day for the past ten years. Her favorite attraction is the "Big Cat Exhibit." Then one day Michelle is injured and cannot visit the zoo. She is at home recovering and wonders about what is in the exhibit today. In the positive condition, over thousands of observations, the cat in the exhibit has always been a jaguar, and Michelle infers that the cat in the exhibit today is a jaguar. In the negative condition, over thou- 
sands of observations, the cat in the exhibit has never been a jaguar, and Michelle infers that the cat in the exhibit today is not a jaguar. Participants were more likely to attribute knowledge in the positive condition.

Another set of studies compared knowledge attributions for logically equivalent statements expressed either positively or negatively (Turri under review). For example, participants were asked whether an agent knows that a bank is either "open" (positive) or "not closed" (negative), whether an agent knows that a previously observed animal is "still there" (positive) or "not gone" (negative), and whether an agent knows that a set of rules "are still the same" (positive) or "have not changed" (negative). Participants were significantly more likely to attribute knowledge when the outcome was described positively than when it was described negatively. Researchers looked for evidence that this asymmetry was due to other judgments that might inform knowledge attributions, such as judgments about truth and probability, but they did not observe a similar effect for these judgments. Researchers also looked for evidence that the asymmetry was due to a more general effect on theory-of-mind judgments. More specifically, they looked for a similar effect on belief attributions (phrased in terms of whether the agent "thinks" something), but they did not find one.

Overall, then, the evidence suggests that in commonsense epistemology, negative facts are harder to know than positive facts. The negative-positive asymmetry is stark when evaluating inference; it abates significantly, though perhaps not entirely, when evaluating perception. Moreover, knowledge attributions might be distinctively sensitive to the perceived difference between negative and positive facts. At least, contemporary American adults implicitly view negative 
facts (absence) as harder to know than positive facts (presence). In light of the similar themes in classical Indian epistemology, I hypothesize that this asymmetry is not unique to contemporary American adults but will be found developmentally and cross-culturally. Thus it would be fitting if the cross-cultural component of this hypothesis was tested on contemporary adult residents of India.

Acknowledgments — For helpful feedback and discussion, I thank Wesley Buckwalter, Ashley Keefner, Vanessa Lam, YeounJun Park, Stephen Stich, Angelo Turri, and Sarah Turri. This research was supported by the Social Sciences and Humanities Research Council of Canada, the Ontario Ministry of Economic Development and Innovation, and the Canada Chairs Research program.

\section{References}

Alexander, J. (2012). Experimental Philosophy. Cambridge: Polity.

Anthony, D. W. (2007). The horse, the wheel, and language: how bronze-age riders from the Eurasian steppes shaped the modern world. Princeton: Princeton University Press.

Aristotle. (1941). Nichomachean ethics. (R. McKeon, Ed., W. D. Ross, Trans.).

Austin, J. L. (1956). A plea for excuses. Proceedings of the Aristotelian Society, 57, 1-30.

Beebe, J. R. (2012). Experimental epistemology. In A. Cullison (Ed.), Continuum companion to epistemology (pp. 248-269). Continuum.

Beebe, J. R., \& Monaghan, J. (in press). Epistemic closure in folk epistemology. In J. Knobe, T. 
Lombrozo, \& S. Nichols (Eds.), Oxford Studies in Epistemology (Vol. 2). Oxford: Oxford University Press.

Bhatt, G. P. (1989). The basic ways of knowing: an in-depth study of Kumārila's contribution to Indian epistemology (2nd ed.). Delhi: Motilal Banarsidass.

Bhattacharya, R. (2002). Cārvāka fragments: a new collection. Journal of Indian Philosophy, 30, $597-640$.

Buckwalter, W., \& Turri, J. (2016). In the thick of moral motivation. Review of Philosophy and Psychology. http://doi.org/10.1007/s13164-016-0306-3

Buckwalter, W., \& Turri, J. (in press). Modest scientism in philosophy. In J. R. Ridder, R. Peels, \& R. van Woudenberg (Eds.), Scientism: prospects and problems. Oxford University Press.

Buckwalter, W., Rose, D., \& Turri, J. (2015). Belief through thick and thin. Nous, 49(4), 748775. http://doi.org/10.1111/nous. 12048

Call, J., \& Tomasello, M. (2008). Does the chimpanzee have a theory of mind? 30 years later. Trends in Cognitive Sciences, 12(5), 187-192.

Clément, F., Koenig, M., \& Harris, P. (2004). The ontogenesis of trust. Mind \& Language, 19(4), $360-379$.

Corriveau, K. H., Meints, K., \& Harris, P. L. (2009). Early tracking of informant accuracy and inaccuracy. British Journal of Developmental Psychology, 27(2), 331-342. http://doi.org/ $10.1348 / 026151008 X 310229$

Corriveau, K., \& Harris, P. L. (2009). Preschoolers continue to trust a more accurate informant 1 
week after exposure to accuracy information. Developmental Science, 12(1), 188-193. http://doi.org/10.1111/j.1467-7687.2008.00763.x

Craig, E. (1990). Knowledge and the state of nature: an essay in conceptual synthesis. Oxford: Oxford University Press.

Cushman, F., \& Greene, J. D. (2012). Finding faults: How moral dilemmas illuminate cognitive structure. Social Neuroscience, 7(3), 269-279. http://doi.org/ $10.1080 / 17470919.2011 .614000$

Dasti, M. R. (2012). Parasitism and disjunctivism in Nyāya epistemology. Philosophy East and West, 62(1), 1-15.

Dasti, M. R. (2017). Nyaya. Retrieved January 2017, from http://www.iep.utm.edu/nyaya/\#SH1e Dhirendra, S. (1966). Epistemological negative dialectics of indian logic - "abhāva" versus "anupalabdh". Indo-Iranian Journal, 9(3), 291-300.

Flombaum, J. I., \& Santos, L. R. (2005). Rhesus Monkeys Attribute Perceptions to Others. Current Biology, 15(5), 447-452. http://doi.org/10.1016/j.cub.2004.12.076

Ganeri, J. (1990). Dharmakīrti on inference and properties. Journal of Indian Philosophy, 18(3), $237-247$.

Gautama. (200/1913). Nyāya Sūtras. (B. D. Basu, Ed.; various Sanskrit scholars, Trans.). Allahabad: Sudhindranatha Vasu.

Gokhale, P. (1978). The philosophical position of Jayarasibhatta. Indian Philosophical Qurterly, 5(3), 489-498.

Goldman, A. I. (1993). Epistemic folkways and scientific epistemology. Philosophical Issues, 3 , 
$271-285$.

Greco, J. (2010). Achieving knowledge: A virtue-theoretic account of epistemic normativity. Cambridge: Cambridge University Press.

Hall, K., Oram, M. W., Campbell, M. W., Eppley, T. M., Byrne, R. W., \& de Waal, F. B. M. (2016). Chimpanzee uses manipulative gaze cues to conceal and reveal information to foraging competitor. American Journal of Primatology, 79(3), e22622. http://doi.org/ 10.1002/ajp.22622

Hare, B., Call, J., Agnetta, B., \& Tomasello, M. (2000). Chimpanzees know what conspecifics do and do not see. Animal Behaviour, 59(4), 771-785. http://doi.org/10.1006/anbe. 1999.1377

Hume, D. (1993). An enquiry concerning human understanding. (E. Steinberg, Ed.) (2nd ed.). Indianapolis: Hackett.

James, W. (1889). The psychology of belief. Mind, 14(55), 321-352.

Jaswal, V. K., \& Neely, L. A. (2006). Adults don't always know best: preschoolers use past reliability over age when learning new words. Psychological Science, 17(9), 757-758. http:// doi.org/10.1111/j.1467-9280.2006.01778.x

Kaminski, J., Call, J., \& Tomasello, M. (2008). Chimpanzees know what others know, but not what they believe. Cognition, 109, 224-234.

Kim, S., Paulus, M., \& Kalish, C. (2016). Young children's reliance on information from inaccurate informants. Cognitive Science. http://doi.org/10.1111/cogs.12471

Knobe, J., Buckwalter, W., Nichols, S., Robbins, P., Sarkissian, H., \& Sommers, T. (2012). Ex- 
perimental Philosophy. Annual Review of Psychology, 63(1), 81-99. http://doi.org/ 10.1146/annurev-psych-120710-100350

Koenig, M. A., \& Harris, P. L. (2005). Preschoolers mistrust ignorant and inaccurate speakers. Child Development, 76(6), 1261-1277.

Koenig, M. A., Clément, F., \& Harris, P. L. (2004). Trust in testimony: children's use of true and false statements. Psychological Science, 15(10), 694-698.

Lillard, A. (1998). Ethnopsychologies: cultural variations in theories of mind. Psychological Bulletin, 123(1), 3-32.

Machery, E., Stich, S., Rose, D., Chatterjee, A., Karasawa, K., Struchiner, N., et al. (in press). Gettier across cultures. Noûs.

Mallory, J. P., \& Adams, D. Q. (2006). The Oxford introduction to Proto-Indo-European and the Proto-Indo-European world. Oxford: Oxford University Press.

Marticorena, D. C. W., Ruiz, A. M., Mukerji, C., Goddu, A., \& Santos, L. R. (2011). Monkeys represent others' knowledge but not their beliefs. Developmental Science, 14(6), 14061416. http://doi.org/10.1111/j.1467-7687.2011.01085.x

Martin, A., \& Santos, L. R. (2016). What cognitive representations support primate theory of mind? Trends in Cognitive Sciences, 1-8. http://doi.org/10.1016/j.tics.2016.03.005

Melis, A. P., Call, J., \& Tomasello, M. (2006). Chimpanzees conceal visual and auditory information from others. Journal of Comparative Psychology, 120(2), 154. http://doi.org/ $10.1037 / 0735-7036.120 .2 .154$

Kim, M., \& Yuan, Y. (ms). Cross-cultural universality of knowledge attributions. Yale University. 
Monier-Williams, M. (1964). A Sanskrit-English dictionary. Oxford: Oxford University Press.

Murray, D., Sytsma, J., \& Livengood, J. (2013). God knows (but does God believe?). Philosophical Studies, 166(1), 83-107. http://doi.org/10.1007/s11098-012-0022-5

Myers-Schulz, B., \& Schwitzgebel, E. (2013). Knowing that P without believing that P. Nous, 47(2), 371-384.

Nichols, S., Stich, S., \& Weinberg, J. M. (2003). Meta-skepticism: meditations on ethno-epistemology. In Collected Papers, Volume 2: Knowledge, Rationality, and Morality, 1978-2010. Oxford University Press. http://doi.org/10.1093/acprof:oso/ 9780199733477.001 .0001

O'Neill, D. K., Astington, J. W., \& Flavell, J. H. (1992). Young Children's Understanding of the Role That Sensory Experiences Play in Knowledge Acquisition. Child Development, 63(2), 474-490. http://doi.org/10.1111/j.1467-8624.1992.tb01641.x

Patil, P. G. (2009). Against a Hindu god: Buddhist philosophy of religion in India. New York: Columbia University Press.

Phillips, J., Knobe, J., \& Cushman, F. (2015). Knowledge before belief: response-times indicate evaluations of knowledge prior to belief. Presented at the 41 st annual meeting of the Society for Philosophy and Psychology, Durham, NC.

Phillips, S. (2015). Epistemology in classical indian philosophy. Retrieved January 2017, from https://plato.stanford.edu/entries/epistemology-india/

Pillow, B. H. (1989). Early understanding of perception as a source of knowledge. Journal of Experimental Child Psychology, 47(1), 116-129. http://doi.org/ 


\section{$10.1016 / 0022-0965(89) 90066-0$}

Puligandla, R. (1996). Fundamentals of Indian philosophy. New Delhi: D.K. Printworld.

Rakoczy, H. (2009). Executive function and the development of belief-desire psychology. Developmental Science, 13(4), 648-661. http://doi.org/10.1111/j.1467-7687.2009.00922.x

Reid, T. (1997). An inquiry into the human mind on the principles of common sense. (D. R. Brookes, Ed.). University Park, Penn.: Pennsylvania State University Press.

Rose, D., Machery, E., Stich, S., et al. (in press). Nothing at stake in knowledge. Noûs.

Santos, L. R., Nissen, A. G., \& Ferrugia, J. A. (2006). Rhesus monkeys, Macaca mulatta, know what others can and cannot hear. Animal Behaviour, 71(5), 1175-1181. http://doi.org/ 10.1016/j.anbehav.2005.10.007

Schmelz, M., Call, J., \& Tomasello, M. (2011). Chimpanzees know that others make inferences. Proceedings of the National Academy of Sciences, 108(7), 3077-3079. http://doi.org/ 10.1073/pnas. 1000469108

Seed, A., \& Tomasello, M. (2010). Primate Cognition. Topics in Cognitive Science, 2(3), 407419. http://doi.org/10.1111/j.1756-8765.2010.01099.x

Sellars, W. (1963). Science, perception and reality. Atascadero, CA: Ridgeview Publishing Company.

Shahaeian, A., Peterson, C. C., Slaughter, V., \& Wellman, H. M. (2011). Culture and the sequence of steps in theory of mind development. Developmental Psychology, 47(5), 1239-1247. http://doi.org/10.1037/a0023899

Southgate, V., \& Vernetti, A. (2014). Belief-based action prediction in preverbal infants. Cogni- 
tion, 130(1), 1-10. http://doi.org/10.1016/j.cognition.2013.08.008

Sytsma, J., \& Buckwalter, W. (Eds.). (2016). A companion to experimental philosophy. Malden, Mass.: Wiley Blackwell.

Sytsma, J., \& Livengood, J. (2015). The theory and practice of experimental philosophy. Peterborough: Broadview Press.

Turri, J. (2011). Believing for a reason. Erkenntnis, 74(3), 383-397. http://doi.org/10.1007/ s10670-011-9271-5

Turri, J. (2012). Review of: Achieving Knowledge: A Virtue-Theoretic Account of Epistemic Normativity, by John Greco. Mind, 121(481), 183-187. http://doi.org/10.1093/mind/ fzs032

Turri, J. (2013). A conspicuous art: putting Gettier to the test. Philosophers' Imprint, 13(10), 116.

Turri, J. (2015a). An open and shut case: epistemic closure in the manifest image. Philosophers' Imprint, 15(2), 1-18.

Turri, J. (2015b). From virtue epistemology to abilism: theoretical and empirical developments. In C. B. Miller, M. R. Furr, A. Knobel, \& W. Fleeson (Eds.), Character: new directions from philosophy, psychology, and theology (pp. 315-330). Oxford University Press.

Turri, J. (2015c). Skeptical appeal: the source-content bias. Cognitive Science, 39(2), 307-324. http://doi.org/10.1111/cogs.12153

Turri, J. (2015d). Unreliable knowledge. Philosophy and Phenomenological Research, 90(3), 529-545. http://doi.org/10.1111/phpr.12064 
Turri, J. (2016a). A new paradigm for epistemology: from reliabilism to abilism. Ergo, 3(8), 189231.

Turri, J. (2016b). Epistemic situationism and cognitive ability. In M. Alfano \& A. Fairweather (Eds.), Epistemic situationism. Oxford: Oxford University Press.

Turri, J. (2016c). How to do better: toward normalizing experimentation in epistemology. In J. Nado (Ed.), Advances in experimental philosophy and philosophical methodology (pp. 35-51). London: Bloomsbury Academic.

Turri, J. (2016d). Knowledge attributions and behavioral predictions. Cognitive Science. http:// doi.org/10.1111/cogs.12469

Turri, J. (2016e). Knowledge judgments in "Gettier” cases. In J. Sytsma \& W. Buckwalter (Eds.), A companion to experimental philosophy (pp. 337-348). Wiley-Blackwell.

Turri, J. (under review). A peculiar and perpetual tendency: an asymmetry in knowledge attribution for affirmations and negations. University of Waterloo.

Turri, J. (in press a). Virtue epistemology and abilism on knowledge. In H. Battaly (Ed.), Routledge handbook of virtue epistemology. New York: Routledge.

Turri, J. (in press b). Primate social cognition and the core human knowledge concept. In E. McCready, M. Mizumoto, J. Stanley, \& S. Stich (Eds.), Epistemology for the rest of the world: linguistic and cultural diversity and epistemology. Oxford University Press.

Turri, J., \& Buckwalter, W. (2017). Descartes's schism, Locke's reunion: completing the pragmatic turn in epistemology. American Philosophical Quarterly, 54(1).

Turri, J., Buckwalter, W., \& Rose, D. (2016). Actionability judgments cause knowledge judg- 
ments. Thought: a Journal of Philosophy, 5(3), 212-222. http://doi.org/10.1002/tht3.213

Wang, J. J., Miletich, D. D., Ramsey, R., \& Samson, D. (2014). Adults see vision to be more informative than it is. Quarterly Journal of Experimental Psychology, 67(12), 2279-2292. http://doi.org/10.1080/17470218.2014.915331

Watkins, C. (2000). The American Heritage dictionary of Indo-European roots. Boston: Houghton Mifflin Harcourt.

Wellman, H. M., Fang, F., Liu, D., Zhu, L., \& Liu, G. (2006). Scaling of theory-of-mind understandings in Chinese children. Psychological Science, 17(12), 1075-1081. 